\title{
Dimensões dos Discursos em uma Empresa Têxtil Mineira(1)
}

\author{
LuizAlex Silva Saraiva \\ Solange Maria Pimenta \\ Maria Laetitia Corrêa
}

\begin{abstract}
Resumo
O objetivo deste artigo é discorrer sobre o que são e como se caracterizam os discursos empresariais e analisar sua relação com as práticas de gestão no contexto empresarial da década de noventa. Teoricamente os discursos empresariais foram explorados no que diz respeito à sua concepção, origens e usos no meio organizacional, o que contribuiu para caracterizá-los como alguns dos principais componentes da gestão contemporânea. Foi adotada uma estratégia metodológica qualitativa para a consecução dos objetivos do trabalho, incluindo análise documental e entrevistas com gestores e trabalhadores de uma empresa têxtil de Minas Gerais. Os principais resultados revelam uma dinâmica complexa, na qual freqüentemente o discurso é absorvido pelos empregados de forma parcial, diferente dos propósitos organizacionais, o que, de forma contraditória, fortalece a empresa em um quadro de enfraquecimento dos trabalhadores. As divergências encontradas, em uma organização ao mesmo tempo conservadora e inovadora, tal qual o ambiente que a circunda, revelam um espaço para a análise das possíveis formas locais de desenvolvimento da gestão.
\end{abstract}

Palavras-chave: práticas de gestão; discurso empresarial; controle organizacional.

\begin{abstract}
This article deals with organizational discourses, trying to understand what are them, how they can be characterized and analyzed associated to management practices in business context in the ninety's decade. Theoretically, organizational discourses were explored concerning their conception, roots and uses in organization, what has contributed to highlight their role as one of main components of contemporary management. We adopted a qualitative methodological strategy to achieve our objectives, in what we analyze internal documents associated to interviews with managers and workers of a textile industry of Minas Gerais State. Main results show a complex dynamic, in what discourse is absorbed by workers of a partial way, not according organizational goals, what, however, strengthens enterprise in a weakness' workers context. Asymmetries found in a conservative and at the same time innovative organization, as the ambient surround it, reveals a promissory space to analyze local forms of management development.
\end{abstract}

Key words: management practices; management discourse; organizational control. 


\section{INTRODUÇÃO}

Os pressupostos neoliberais encerrados nas idéias de globalização e de reestruturação produtiva têm trazido desafios expressivos para as organizações, porquanto, como em nenhum período da história, as transformações são colocadas como condições de sobrevivência, a fim de que os atores (empresas, trabalhadores e, em certo sentido, até mesmo governos) permaneçam no jogo, ditado prioritariamente pelo mercado. A maior parte dos argumentos utilizados recai sobre a inexorabilidade do neoliberalismo, criticada por Faria (2000), que forçaria as empresas a se adaptarem às pressões - ocultas ou expostas - provenientes do ambiente macroeconômico, disseminando um discurso sobre a competitividade que transforma em pressão histórica o que até bem pouco tempo era escolha empresarial (Pimenta, 1999).

Nesse novo quadro, o investimento em tecnologia produtiva não traz todas as respostas, uma vez que, isoladamente, já não garante diferenciais expressivos de competitividade como no passado. A tecnologia está associada a alterações em dimensão mais abrangente - a gestão - abalando com isso a ordem e o status convencionais. Qualquer que seja o objetivo prioritário das mudanças, contudo, é fundamental manter na organização uma parcela extra de aparatos para a manutenção de um espaço de dominação. Em geral, isso significa a circunscrição dos trabalhadores aos limites que os gestores julgam adequados, pois a existência de vias alternativas de ação e de formas diferenciadas de oposição ao sistema estabelecido e suas inadequações passa a ser um indicativo do que deve ser controlado, a fim de garantir a harmonia organizacional ${ }^{(2)}$.

Nesse quadro, o discurso emerge como importante ferramenta da organização, sendo condição para o seu prestígio e eficiência a afirmação e aceitação tácita da incompetência dos trabalhadores enquanto sujeitos sociais e políticos ${ }^{(3)}$. Para que esse discurso possa ser proferido e mantido, é imprescindível que não haja sujeitos, mas apenas homens reduzidos à condição de objetos sociais (Chauí, 2001), portanto, naturalmente ajustáveis.

Como um elemento central da nova gestão empresarial, o discurso passa a ser produzido - ou em alguns casos, incrementado - com propósito bem definido: conseguir cooperação. Como sustenta Pimenta (1999, p.137), “sejam sujeitos, é 
a nova palavra de ordem”. Mais do que indicar agora um tipo desejável de comportamento, essa perspectiva passa a valorizar, como um imperativo, a sujeição dos trabalhadores às atuais (e futuras) demandas organizacionais. Isso significa a construção social de sujeitos direcionados (ou subordinados) aos interesses da organização.

Todavia não é isso que o discurso empresarial postula. Embora parta do pressuposto da incapacidade de homens - que precisam ser regidos pela organização, que sabe o que é melhor para eles - os argumentos utilizados reforçam sistematicamente o papel do trabalhador enquanto cidadão, inserto em uma democracia organizacional (Faria, 2002). Essa retórica precisa ser utilizada aparentemente para dar suporte à idéia de que a organização é um ambiente compartilhado eqüitativamente por todos, a fim de reforçar as imagens de harmonia e igualdade (Faria, 2000) - preceito democrático na raiz - necessárias à noção de cooperação e de melhores resultados.

Contudo, conforme salienta Souza-Lobo (1993), o discurso dos trabalhadores vem desmistificar tal visão, porque, ao tentar desfrutar na empresa os direitos de que gozam na sociedade, percebem certo sentimento de ilegitimidade pela reivindicação da cidadania, isto é, por lutar por seus direitos sociais e políticos no interior da fábrica. Isso entra em contradição com o que é tão freqüentemente colocado pelo discurso da administração, pois se verifica a existência de práticas empresariais moralmente conflituosas com os preceitos legítimos da demoracia e da ética (Faria, 2000).

Com base nos pontos levantados, este artigo pretende, logo após detalhar os procedimentos metodológicos adotados, discorrer sobre o que são e como se têm caracterizado os discursos empresariais nas suas diversas instâncias dentro da organização. A seguir, são tratadas as raízes dessa matriz discursiva, que fornecem suporte para o desenvolvimento de tais dimensões relacionadas ao discurso na organização. Em seguida, são tratados os usos do discurso, e suas diversas manifestações no meio organizacional, seguidas das considerações finais do estudo.

\section{Procedimentos metodológicos}

Para atender aos objetivos propostos, foi estudado o caso de uma organização industrial têxtil de Minas Gerais. O estudo de caso é indicado em função da 
possibilidade de aprofundamento do estudo e de visualização de conceitos. A estreita ligação entre unidade de análise e definição do caso estudado reside no fato de que esta técnica se propõe a "adquirir conhecimento do fenômeno adequadamente a partir da exploração intensa de um único caso” (Becker, 1999, p.117). Além de indicação teórica, foram levadas em consideração limitações de ordem prática. Esta técnica é a mais adequada à natureza do problema e é objetivamente inviável realizar um survey com todas as empresas têxteis mineiras no âmbito dos recursos de que se dispõe.

A estratégia qualitativa é caracteristicamente multimetodológica e, por isso, esta pesquisa focalizou inicialmente o material formal produzido pela empresa, em particular diversos números do jornal interno ${ }^{(4)}$. Pôde-se perceber o seu uso como uma das principais vias de escoamento do discurso da organização, uma vez que é a palavra oficial dos dirigentes a respeito do cotidiano organizacional. Na segunda parte, na pesquisa de campo propriamente dita, foram efetuadas entrevistas semi-estruturadas, obedecendo ao critério de amostragem nãoprobabilística intencional, utilizado quando uma amostra é escolhida propositadamente em virtude de possuir características consideradas relevantes para a observação do fenômeno. Na seleção dos gestores, considerou-se seu papel na gestão e sua influência na concepção dos discursos e práticas de gestão. A maior preocupação no caso dos trabalhadores foi garantir que os entrevistados estivessem alocados em todas as fases do processo produtivo, embora estudos qualitativos não tenham maior compromisso com a questão da representatividade da amostra. As entrevistas foram realizadas com gestores dos níveis estratégico, tático e operacional e com trabalhadores em pesquisa de campo subdividida em três fases, realizadas em unidades distintas da organização, tendo sido entrevistados no total 15 gestores e 24 trabalhadores.

Embora as entrevistas tenham sido submetidas a um processo sistemático de interpretação, de modo a captar os diversos matizes dos discursos emitidos e absorvidos na organização, a análise do discurso, cuja técnica consiste em "certo número de operações de desmembramento e de classificação semânticas, sintáticas e lógicas simultaneamente” (Bardin, 1995, p.217), não foi considerada como método adequado para tal fim, em função do fato de que nessa visão os resultados são pobres “em virtude da adoção de uma certa metodologia de análise dos dados decorrente de uma certa teoria da língua que claramente não se presta a confirmar explicitamente as intuições dos analistas políticos em relação aos discursos” (Possenti, 1993, p. 20). Optou-se por minimizar a quantificação, uma vez que a preocupação central foi a de garantir a análise da influência das diversas 
variáveis internas e externas sobre o objeto de estudo. Nada melhor, portanto, que dar ênfase à própria fala dos entrevistados.

Por se tratar de estratégia essencialmente qualitativa, a análise dos dados não se propôs extrapolar os limites da organização estudada e fazer generalizações a respeito de todo o setor têxtil mineiro. Assim, tomou-se o cuidado de evitar que as conclusões fossem extrapoladas para o setor. Entretanto, mesmo levando em consideração a diversidade existente no parque industrial têxtil do Estado, é possível fazer algumas comparações mais amplas, mediante a apreciação específica dos fatos e tendências observadas em um dos maiores e mais importantes grupos têxteis nacionais, a seguir caracterizado ${ }^{(5)}$.

\section{O Caso Analisado}

A Empresa Mineira de Tecidos (EMT) ${ }^{(6)}$, uma das mais tradicionais do setor têxtil brasileiro, cresceu incorporando empresas em situação problemática, o que constituiu simultaneamente um estratégia de consolidação de bons negócios e de absorção de competências específicas das empresas adquiridas, sempre incorporadas à forma vigente de gestão. Assim, embora existam unidades industriais localizadas em cidades distintas, as características gerais da empresa foram preservadas, não havendo expressivas variações de uma unidade para a outra, o que se deve, em parte, ao senso a respeito do valor que possui o fato de pertencer à grande família emitense. Isso não apenas foi um trabalho efetuado pelos dirigentes da empresa, como cultuado como respeito às mais

altas tradições da família Santos ${ }^{(7)}$, controladora da empresa desde a sua fundação ${ }^{(8)}$.

É visível a preocupação da EMT com a preservação do seu espaço entre as empresas têxteis fadadas a sobreviver no mercado atual. O balanço de 1998 expressa tal preocupação, ao apontar "investimentos da ordem de US\$ 70 milhões nos cinco anos anteriores, na expansão e modernização de seu parque industrial” (Corrêa e Pimenta, 2000, p. 14). Desde 1985, têm sido empreendidos esforços sistemáticos de modernização tecnológica das suas plantas industriais, o que se verifica tanto pela introdução de sistemas de automação de base microeletrônica, em um primeiro momento, quanto pela utilização de novas tecnologias de gestão ${ }^{(9)}$ a partir dos anos noventa, processos que, aliados, têm trazido resultados considerados bastante positivos pela cúpula da organização, a exemplo do 
recebimento - pioneiro na indústria têxtil da América Latina - de uma certificação internacional de qualidade (ISO 9000), válida para todo o processo produtivo.

Esse esforço se manifesta na $8^{a}$ posição do mercado têxtil brasileiro. Em 1999, a EMT faturou 156 milhões de reais e produzido 44 milhões de metros de tecido. Conta com 1.500 empregados, número 40\% menor do que em 1993, dos quais 26\% atualmente é mão-de-obra feminina (Corrêa e Pimenta, 2000). Tais esforços de redimensionamento constante das atividades se devem, entre outros aspectos, à estratégia da organização de se tornar uma empresa de classe mundial, em conseqüência da necessidade de se adequar às demandas propostas pela globalização e pela reestruturação produtiva.

\section{Algumas Palavras sobre o Discurso Empresarial}

Na condição de manifestação essencialmente local, embora sem dúvida conectada com o que ocorre em termos globais, o discurso observado nas empresas não está, de forma alguma, dissociado da realidade que o circunda. Se é “essencialista, normativo, prescritivo e pedagógico”, como afirma Chauí (1989, p. 109), o é porque se insere em ambiente não apenas permeável à proliferação dessa retórica, mas também conivente, porque lhe é semelhante.

A gestão empregada na EMT se encaixa nesse enfoque, em particular no que se refere à disseminação de uma espécie de pedagogia da fábrica, em que os procedimentos e o comportamento que o trabalhador precisa ter são ensinados e aprendidos, conforme Enriquez (1974; 1997). Daí a situação a seguir mencionada, em que a administração precisa ser auxiliada por outra ciência, específica para a formação do perfil desejado da mão-de-obra:

"Foi uma exigência da fábrica que eu fizesse pedagogia. Talvez porque tem uma área bem ligada ao humano, à parte de ensino, é uma coisa que eu vou ter que fazer muito aqui é ensinar as pessoas” (Gestor K).

Dessa maneira, "as relações sociais que se reproduzem nas organizações confirmam e reforçam a estrutura social” (Prestes Motta, 1992, p. 39; Enriquez, 1997). A sociedade brasileira, meio no qual se inserem as organizações contemporâneas, que aqui são analisadas na sua dimensão gestionária, permite a manifestação de práticas autoritárias porque é, em seu âmago, autoritária também. "Ela tem-se valido, de forma alternativa, da força militar tradicional e do poder 
racional-legal para o estabelecimento e manutenção da autoridade, criando assim uma cultura de concentração do poder baseada na hierarquia/subordinação” (Prates e Barros, 1997, p. 59).

Sem dúvida, o meio no qual as organizações estão insertas atua como configurador da sua gestão (Ansart, 1977). Entretanto, atribuir-lhe todas as responsabilidades pela caracterização da gestão, e mais especificamente pela disseminação dos discursos atualmente vigentes nas organizações é um equívoco. Podem ser observados na composição dos discursos empresariais muito mais do que apenas fatores externos.

Embora contraditório na sua essência, o discurso, uma das instâncias manifestas (Faria, 2002), torna-se terreno fértil e ativamente utilizado pela organização para tentar remover dos trabalhadores as intenções de questionar a ordem vigente, bem como para tentar incutir em suas mentes a noção de parceria incondicional entre capital e trabalho, imagem que, buscando a metáfora da indivisão, só reforça o paternalismo e autoritarismo da cultura empresarial brasileira. As empresas procuram, dessa forma, incorporar os discursos dos trabalhadores de maneira a reduzir as disparidades entre suas necessidades e as demandas empresariais, fazendo com que haja redução das contradições individuais e organizacionais. Na EMT, a visão que a empresa possui dos trabalhadores, de acordo com um deles, é a de que eles

“seriam parceiros, parceiros de negócio. Já houve época em que tinha um relacionamento mais próximo, mais família, a indústria quando começou aqui era só EMT, uma família. Hoje é mais profissional” (Trabalhador 24).

O discurso utilizado pela organização possui, desse modo, alguns elementos peculiares que, combinados (e inseridos) em uma estratégia empresarial mais ampla, possuem o intuito de mobilizar os trabalhadores em prol de objetivos organizacionais. Não é possível afirmar, todavia, que se trata apenas da manifestação de um único discurso organizacional. Trata-se de discursos, no plural, uma vez que é equivocado tratar de singularidade em fenômeno desse nível de sofisticação e manifestando por meio de expressiva pluralidade de linhas de ação. Mesmo as mais competentes articulações retóricas, elaboradas pela organização, ainda sofrem interpretação e reinterpretação de acordo com as condições objetivas do meio no qual se pretende disseminá-lo (Enriquez, 1997). O discurso da organização, portanto, embora seja coerente e alinhado, não é uno, porque se presta a adaptações e leituras diversas no seu processo de difusão. 
Os discursos possuem inúmeros desdobramentos que, embora se apresentem de maneira articulada, não são semelhantes nem pretendem sê-lo. Assim, o discurso da sobrevivência ressalta a fragilidade organizacional, pois mesmo que todas as medidas cabíveis tenham sido tomadas na intenção de modernizar a empresa - o que normalmente inclui o remodelamento da organização e a extinção de cargos e empregos em massa - ainda assim, a empresa está sujeita a qualquer tipo de vibração mais forte proveniente do mercado, em particular mudanças oriundas dos mercados internacionais ${ }^{(10)}$. A qualidade, a produtividade e a competitividade, que são alguns dos discursos empresariais mais freqüentemente difundidos, como se fossem uma espécie de panacéia organizacional, destacamse pela sua articulação intrínseca, enquanto explicações para a forma que tem tomado a competição: produtos com baixo nível de qualidade tendem a ser rejeitados pelo mercado, que é, em última instância, quem decide se as empresas vão perecer ou não. Tais produtos, além de apresentar qualidade ${ }^{(11)}$, precisam estar fortemente baseados em níveis de produtividade elevados, a fim de que proporcionem elevado potencial de competitividade, para que a empresa se mantenha em condições de disputar fatias de mercado com seus concorrentes.

Esses fatores, contudo, não esgotam as facetas dos muitos discursos empresariais utilizados. Só é possível atender às suas demandas, se for possível às organizações disseminar - e terem interiorizados pelos seus membros - seus discursos de integração e de cooperação. Integração, porque sem mão-de-obra efetivamente integrada a um projeto comum, sem a noção de que está ligada a um objetivo mais amplo, de manter viva a sua comunidade produtiva, não há como conseguir resultados positivos. Além disso, essa mão-de-obra precisa ter em mente a idéia de cooperação, de que necessita trabalhar junto com a organização, não lhe criando problemas, ou seja, não questionando a ordem vigente, a fim de que possam desfrutar de benefícios mútuos com o alcance de resultados. A cooperação, tão necessária à manutenção dos propósitos organizacionais, passa essencialmente por um exercício cotidiano de definição e de redefinição dos papéis atribuídos aos elementos da comunicação formal da organização. Na condição de proprietária e usuária por excelência dos meios formais de comunicação existentes na organização, a empresa faz uso desses recursos de maneira a perpetuar sua dominação sobre os trabalhadores ${ }^{(12)}$.

Como seu intuito é o de manter elevados níveis de cooperação, a fim de que todos os membros compartilhem o objetivo comum, a organização articula vários discursos, que operam em diversas frentes, objetivando apoio incondicional aos seus intentos. Como coloca Chauí (1989, p. 31-32): 
"A estrutura do campo comunicativo, destinada a produzir o sentimento da comunicabilidade plena, da participação e da comunicação, não é um processo de constituição recíproca dos interlocutores, mas antecede, regula, controla e predetermina a própria comunicação. O espaço é anterior aos seus ocupantes, não é criado ou recriado por eles segundo a lógica peculiar ao ato comunicativo".

Ao ressaltar o uso que as organizações fazem de sua estrutura formal de comunicação, Freddo (1994, p. 27) observa que os discursos das organizações propõem “uma nova divisão entre aqueles que falam e aqueles que ouvem”, uma espécie de redimensionamento do princípio taylorista da especialização funcional, em que alguns executam (os trabalhadores) o que outros planejam (os gestores) ${ }^{(13)}$. Isso seria uma característica das sociedades industriais, em que os trabalhos manuais e intelectuais "são pensados e vivenciados como realidades profundamente distintas e distantes uma da outra" (Arantes, 1998, p. 18). Tal visão é compartilhada por Enriquez (1974) e Prestes Motta (1991), ao postular que na empresa os empregados têm o direito de se pronunciar apenas sobre assuntos definidos como da sua competência. É a esfera da dominação manifesta até mesmo - e por que não dizer, soberanamente - na dimensão comunicacional. Entender tais manifestações auxilia a compreensão dos discursos e de suas dimensões; contudo tais aspectos não são sinônimos, sendo aqui necessário aprofundar a discussão sobre os discursos empresariais.

\section{Raízes da Matriz Discursiva}

Os discursos estão intimamente relacionados à forma pela qual a organização orienta os indivíduos para a consecução dos seus objetivos, já que exigem o desempenho de papéis predeterminados, padronizados, impostos por meio de formas variadas de controle. O papel dos gestores seria o de impor, de modo sutil - e permanente - mediante a utilização dos discursos, padrões, normas, comportamentos, crenças e valores que dizem respeito à esfera política da organização, mais especificamente ao exercício do poder (Freddo, 1994). Seu papel, entre outros aspectos, é o de deixar evidente aos seus destinatários quem de fato detém e exerce o poder e quem, por conseguinte, tem de submeter-se a ele para continuar existindo enquanto membro da organização (Ansart, 1977). Como Prestes Motta (1992, p. 42) alerta, "é preciso notar que a ideologia está sempre a serviço de um projeto, que se traduz em uma prática política”. 
Os dirigentes desempenham papel de cunho político, em particular no que se refere à capacidade que possuem de tornar hegemônicos os interesses particulares da organização, de apresentar como sendo do interesse dos indivíduos aquilo que é somente de interesse organizacional (Enriquez, 1997). Esta perspectiva mascara a verdadeira forma de atuação das organizações, em que "as decisões estratégicas não são submetidas à sociedade em nome da vontade geral, pois se trata de decisões estratégicas privadas” (Faria, 2002, p. 11). A idéia subjacente à institucionalização e proliferação de uma matriz discursiva liga-se ao fato de que os dirigentes estão envolvidos em processo político que envolve o controle totalitário da natureza, o processo de produção e dominação dos homens, para tanto "desempenhando um papel que se encontra antecipadamente definido, no qual seu discurso tem uma face oculta, escondida, um não dito que representa o inconsciente político da organização” (Freddo, 1994, p. 26).

Os discursos se apresentam, portanto, como ações essencialmente estratégicas, nas quais o locutor procura exercer o poder sobre o ator por meio de ameaças de coação, tanto internas quanto externas, por meio da deformação da ação comunicativa que pretende estabelecer. $\mathrm{O}$ que se quer, de fato, ainda que em muitos casos isso não seja mencionado de forma clara, é a busca de poder sobre os indivíduos, com o intuito de conseguir sua cooperação ${ }^{(14)}$. Vistos sob esse ângulo, os discursos nada mais representam do que o exercício da influência sobre os comportamento individual e coletivo na organização. Um exemplo disso é o trecho abaixo, publicado originalmente em um dos veículos de comunicação formal da empresa:

“A melhora registrada só foi possível graças ao empenho de cada um dos nossos 1.600 funcionários. Precisamos renovar nossas energias na busca do lucro, que é a condição básica para a nossa sobrevivência no mercado. É nessa direção que devemos encaminhar todos os nossos esforços, utilizando todas as ferramentas e metodologias disponíveis, como o kaizen, o 5s. Os grupos de melhoria, o comitê de peças e até mesmo os programas de integração, que aproximam as pessoas e estreitam os laços dentro da nossa empresa” (Jornal maio/junho 1999).

Por apresentar conteúdo dogmático, ideológico, a matriz discursiva trabalha com a perspectiva de que há meios de transformar os procedimentos impostos pela ação administrativa em comportamentos estáveis e previsíveis, como a obediência às normas e regulamentos da organização, entre outros aspectos. Como salienta Freddo (1994, p. 32), 
“O inconsciente político mostra-nos um discurso que pretende ser racional e não apenas ilude e submete os indivíduos, mas os põe a seu serviço, demandando deles um esforço no sentido de cooperação, onde cooperação, e por conseguinte o processo de alienação, acabará por dizer respeito à manipulação e à doutrinação. O discurso se mostra, portanto, como um discurso a serviço da razão instrumental, da mesma racionalidade que se encontra voltada para o domínio e o controle da natureza, para o desenvolvimento e reprodução das forças produtivas e para o desencantamento do mundo que nos rodeia”.

Ainda assim, a matriz discursiva traz contradições em seu âmago (Faria e Meneghetti, 2001), porquanto, se por um lado deseja alterar comportamentos, por outro procura dissimular tal proposta, ocultando-a sob o manto da integração entre empresa e trabalhador. Sua contradição está em que seu locutor (o gestor) é também, em dado momento, seu ator, isto é, indivíduo como qualquer outro, e não um dirigente, formalmente investido de características que o diferenciam dos demais membros da organização. Nesse sentido, a funcionalidade dos discursos empresariais se manifesta em sua pretensão de manipulação e ocultação dessa intenção, de tal modo que o ator, ofuscado, insista em sua imunidade (Ansart, 1977). Torna-se assim de certa forma coerente a percepção de que é parte das atribuições técnicas dos dirigentes hierárquicos tomar posição a respeito das melhores técnicas de doutrinação da mão-de-obra.

Como os discursos têm função ideológica clara, a de manter a coesão social no caso da empresa, dos seus integrantes sobre os objetivos a serem alcançados - é possível perceber que sua intenção é a de ocultar "o antagonismo básico de um modo de produção, ou seja, sujeitando dominados e justificando dominadores" (Prestes Motta, 1992, p. 41). Isso não quer dizer, naturalmente, que os indivíduos simplesmente se sujeitem a tais articulações de forma passiva e crédula, mas que a eles se tenta negar, a todo instante e pelos canais formais, o acesso ao que ocorre de fato nos subterrâneos administrativos, pois as práticas de gestão normalmente não tratam da questão dos conflitos e, quando o fazem, trazem consigo a intenção de envolver os trabalhadores, fazendo com que os conflitos por eles sentidos sejam reconhecidos como de origem estritamente psicológica, não coletiva, o que limita consideravelmente qualquer ação efetiva de mudança (Pagès et al., 1987; Enriquez, 1974). Entretanto o não reconhecimento ou não legitimação dos conflitos existentes não quer dizer que eles não existam, e que os trabalhadores estariam sendo forjados pela máquina da organização. Na verdade, freqüentemente os conflitos são postos à mostra, como resultado de problemas e 
confrontos velados ou não resolvidos na arena organizacional, conforme Ansart (1977). Na EMT por exemplo,

"Você chegava no nível da gerência, e o nível de competição era altíssimo, mas se você chegava no nível de direção era uma relação super amistosa (...) Eles mesmos não entendiam por que as coisas lá embaixo aconteciam daquela forma. Mas por quê? Por que [o conflito] não era tratado naquele nível. (...) Então o reflexo do que não era tratado nesse nível passava para baixo" (Gestor F).

Melo (1995, p. 171) nesse sentido ressalta que, embora se possa afirmar que as novas tecnologias gerenciais e o controle social dificultem ou mesmo impeçam a organização coletiva e a expressão do conflito, "não é verdade que essa situação de incapacidade possibilite a integração completa dos trabalhadores ao projeto da classe dirigente". Isso seria tirar dos trabalhadores sua capacidade de autonomia, sempre existente por mais adversas que sejam as condições objetivas da empresa ${ }^{(15)}$. A prova disso é que, mesmo com toda a retórica sobre a utilidade e necessidade do kaizen, os trabalhadores preservam para si um espaço próprio, no qual manifestam suas opiniões a respeito dessa técnica:

"Muita gente pensa que o kaizen, tem até uma brincadeira aí em cima que o kaizen é 'Sai cem’ (risos). Eles pensam que vai mandar embora, mas o kaizen, a meta dele não é mandar embora ${ }^{(16) ”}$ (Trabalhador 5).

O certo é que, alienado ou não, o trabalhador nas organizações contemporâneas se encontra fortemente vinculado a uma realidade na qual a matriz discursiva é extensiva e intensivamente utilizada como forma de obtenção de uma integração entre empresa e trabalhadores que atende muito mais aos desígnios da primeira do que às reais necessidades da segunda parte, de forma que a compreensão dos discursos e seus elementos auxiliam o entendimento de boa parte das manifestações organizacionais atuais.

\section{Usos dos Discursos na Organização}

As discrepâncias existentes na organização, ao invés de aparentemente formarem um quadro de perspectivas sombrias para o empresariado, têm-se mostrado como elemento de importância secundária na atual configuração de forças entre empresas e empregados, nesse momento favorável às iniciativas 
empresariais, em detrimento dos esforços dos trabalhadores. Estes, e suas organizações representativas, em sua maioria, continuaram atrelados a estratégias de tempos passados, entre outros aspectos ${ }^{(17)}$. Em geral, isso porque a definição, o uso e a modernização de práticas de gestão são primazia do empresariado e não dos trabalhadores.

Muito do que se verifica como bem sucedido em termos gestionários deve-se ao oportuno acoplamento da gestão a uma matriz discursiva calcada no convencimento da mão-de-obra de que seus interesses são os mesmos interesses da organização, o que esconde "uma rede simbólica de relações de dominação ideológica e de poder” (Faria e Meneghetti, 2001, p. 1). Tal visão destaca as novas formas de trabalho, que dão maior liberdade ao trabalhador, como sinônimo da sua emancipação profissional e política. Veloso et al. (1999, p. 58) defendem que, de certa forma, o que se percebe nos discursos das formas atuais de gestão é "uma busca de suavização do paradoxo entre o cidadão e o operário, procurando difundir as duas categorias e dando possibilidade de o trabalhador opinar na forma como realiza suas tarefas".

A flexibilidade na organização do trabalho e na execução das tarefas é freqüentemente apontada como sendo o sinal de novos tempos, em que a participação dos trabalhadores será sistematicamente estimulada e sua opinião levada em consideração. "Daí toda a importância que adquire não só o discurso, mas o desenvolvimento dos grupos participativos como o elemento principal que vai articular a passagem do informal e clandestino para o formal e controlável” (Pimenta, 1998, p. 110). Assim,

"um novo discurso empresarial se constrói na tentativa de implicar o trabalhador e comprometê-lo com os objetivos da organização, significando não só 'o fim do taylorismo' como paradigma administrativo, mas a possibilidade de 'ascensão' do trabalhador à maioridade cívica, ao 'rank' de cidadão, no aproveitamento do 'homem total' e não mais um homem feito de gestos e da memória desses gestos. Essa nova investida empresarial se dá (...) na necessidade de um novo controle da organização informal em função da importância que vêm adquirindo o indivíduo e o coletivo, como elementos cruciais que, no concreto, no real, fazem realmente funcionar a organização, independente da prescrição e estruturação formal que marca a organização. Esta elasticidade de fronteira tem o objetivo último de transformar a participação informal, que escapa ao controle administrativo, em uma participação aberta, decodificada e sujeita ao controle empresarial” (Pimenta, 1998, p. 106). 
O controle, embora central na discussão dos propósitos sobre os quais estão assentados os discursos na organização, não é capaz de esgotar todas as possibilidades de utilização da matriz discursiva. Embora o controle seja uma peça-chave, naturalmente a dimensão comunicacional permanece relevante nessa nova etapa da gestão organizacional; entretanto o interesse da organização vai muito além do simples fornecimento de informação. De acordo com Chauí (1989, p. 35), no processo de comunicação,

“a informação não se reduz ao aspecto do consumo nem ao da persuasão (...), mas se assenta no desejo de sedução. Esta decorre da capacidade dos meios para nos convencerem de que estamos vendo e ouvindo a produção coletiva de idéias ou de valores (...). A sedução é tanto maior porque corresponde a uma exigência real do espaço democrático, isto é, a circulação pública das informações e a formação de uma opinião pública informada que possa decidir”.

Junta-se às ferramentas da organização a sedução precisamente no momento em que o destaque é dado à subjetividade e ao indivíduo, ainda que este se apresente integrado em grupos, manifesta-se especificamente na esfera da gestão. Como Lima (1995) destaca, as estratégias elaboradas para persuadir os trabalhadores da coerência e da integridade da empresa atualmente são mais sofisticadas do que tempos atrás, uma vez que recorrem à experiência passada das empresas e às últimas descobertas operadas pela psicologia e pela sociologia neste domínio.

A sedução "é aquilo que desloca o sentido do discurso e o desvia de sua verdade" (Baudrillard, 2000, p. 61). Ao ser cotidianamente injetada nas relações sociais e individuais na empresa, "a sombra sedutora do discurso paira hoje sobre o deserto da relação social e do próprio poder” (Baudrillard, 2000, p. 200). Ela constitui a tentativa de dominação do universo simbólico do trabalhador, grande desafio das estratégias de gestão atuais. Ao negarem tal propósito, alegando que o que se quer é despertar a cooperação voluntária, e não seduzir a mão-de-obra, as empresas atingem o que constitui a última metamorfose da sedução, o discurso anti-sedução. O depoimento a seguir demonstra quanto a estratégia empregada na EMT confirma essa visão, destacando que, em si, a organização não deseja pessoas afetivamente comprometidas, quando na verdade é o que se verifica em quase todas as manifestações discursivas por parte dos gestores:

“A gente está com visão forte nas pessoas. a gente não quer mais que eles vistam a camisa da empresa. Essas expressões do passado, a gente 
não quer, a gente quer uma relação profissional. Uma relação justa em termos de um processo ganha-ganha, um processo de respeito a essas pessoas, respeito mesmo. Então nós não procuramos aqui nenhum cara que veste a camisa, não. Não tem um valor mais para a gente como no passado existia esse valor. Hoje em dia a gente quer profissionais atuantes, respeitados e que trabalham em times” (Gestor E).

Os discursos manifestados pela organização têm características trabalhadas, guiadas pela existência de um sentido, a idéia de convencimento dos trabalhadores da convergência de seus interesses individuais com os propósitos organizacionais. A legitimidade de tais discursos baseia-se na estratégia de sedução que os sustenta, que torna os diversos atores organizacionais tanto vítimas quanto produtores de uma "transfiguração das coisas em aparência pura” (Baudrillard, 2000, p. 134), porquanto, se por um lado a produção tem como papel apenas fabricar objetos, signos reais, deles obtendo algum poder, por outro "a sedução produz apenas engano e dele obtém todos os poderes, dentre os quais o de remeter a produção e a realidade ao seu engano fundamental” (Baudrillard, 2000, p. 80).

Uma das ferramentas mais utilizadas nessa etapa do desenvolvimento da organização é o uso maciço de recompensas simbólicas, que têm por função "sustentar positivamente o comportamento e por isso devem ser 'imprevisíveis' e 'intermitentes'” (Lima, 1995, p. 24). As empresas contemporâneas, com isso, reconhecem o trabalhador como interlocutor e, por isso, precisam dar-lhe a impressão de ser respeitado e valorizado, o que não pode ser considerado, sob nenhum aspecto, uma atitude organizacional de caráter casual ou altruísta, uma vez que se insere em quadro estratégico mais abrangente. A gestão atual, ao conceder aos trabalhadores prerrogativas antes impensáveis, na verdade mostra, por meio da sedução, a sua face de repressão absoluta, pois “dando-nos um pouco demais, cortam-nos tudo” (Baudrillard, 2000, p. 38).

O discurso auxilia a compreensão não apenas da ideologia subjacente às organizações, mas também como as organizações exercem influência sobre a sociedade como um todo, utilizando-se de seus membros. Ele procura atuar influenciando a esfera da subjetividade dos trabalhadores, ao apresentar-se como representante da felicidade geral, situação na qual deixaria de existir o indivíduo com capacidade de deliberação, com capacidade de reflexão e com espírito crítico (Freddo, 1994). Nesse sentido, 
“o discurso se apresenta como uma possibilidade de falsificação da consciência na organização, procurando impor-se ao indivíduo no ambiente interno da organização, buscando sua legitimidade através de dois caminhos distintos: primeiro, quando o sujeito reconhece seu conteúdo ideológico, passando a agir de acordo com sua lógica, buscando tirar proveito, procurando levar vantagem vestindo a camisa da empresa; segundo, quando esse conteúdo ideológico é interiorizado, através do consentimento, que é obtido pela doutrinação. O indivíduo não apenas interioriza sua lógica, tomando-a como sua, mas raciocina e se comporta de acordo com essa mesma lógica. O discurso da organização ilude e, por iludir, se mostra falso, pois mente duas vezes: na primeira vez, mente ao seu próprio locutor e, na segunda vez, quando reflete a face oculta de uma prática autoritária, mente para toda a organização” (Freddo, 1994, p. 32).

Isso é conseguido tanto com a utilização da matriz discursiva propriamente dita, quanto por meio da utilização de diversas ferramentas próprias da gestão. Um exemplo disso é dado por Prestes Motta (1992), ao tratar da questão do desenvolvimento das qualificações necessárias ao desempenho de diversas funções organizacionais, o que é conseguido mediante o treinamento. Este opera em dois níveis, sendo que somente o primeiro diz respeito, de forma mais direta, às habilidades técnicas ligadas ao exercício da função. O segundo nível, de caráter mais ideológico, refere-se à internalização pelos membros da empresa de determinados comportamentos necessários, que contribuem para a mudança da imagem que os indivíduos têm de si próprios.

A alienação passa a operar a partir de tal lacuna, da modificação, ainda que lenta e sutil, mas sistemática, da auto-imagem dos trabalhadores. Estes passam a se enxergar como dependentes da organização e incapazes de conseguir melhores oportunidades de trabalho ou mesmo de desempenhar suas atividades com maior criatividade e dinamismo. O resultado disso é a submissão, levando a uma espécie de satisfação tolhida com a empresa e com a atividade profissional, uma vez que não são o que idealmente exploraria todo o potencial dos trabalhadores, mas na realidade representam tudo o que eles possuem:

“A EMT hoje para mim é tudo na minha vida. Depois, ela é minha segunda casa” (Trabalhador 8).

"Eu acho que foi a melhor coisa que aconteceu na minha vida" (Trabalhador 4). 
"A fábrica faz parte da minha vida. Eu me sinto como parte da fábrica" (Trabalhador 24).

“A EMT é o meu segundo lar. É o meu segundo lar, aqui que eu, a gente tira o pão de cada dia. Aqui que você tira sua roupa, tira seu carro, sua casa (...) para mim é praticamente mais em casa do que lá em casa” (Trabalhador 13).

A noção de harmonia subjacente a toda idéia de gestão sem conflitos, de discurso que procura projetar essa imagem, tem suas raízes históricas nas próprias características locais. A empresa, por produzir e reproduzir os valores presentes no meio em que se insere, está inserida, traz ao seu cotidiano manifestações similares dos acontecimentos desenrolados na sociedade da qual faz parte.

\section{Considerações Finais}

O objetivo deste artigo foi o de analisar os relacionamentos existentes entre os discursos e as práticas de gestão no contexto empresarial da década de noventa. Os resultados encontrados permitem afirmar que não apenas há contradições, de fato, mas que existem à revelia de suposta coerência: a organização analisada é exemplo de boa administração, tendo desempenho acima da média, o que é refletido não apenas no nível de investimento dos últimos anos, como pelo reconhecimento do mercado, em que cada ano aumenta sua participação. A despeito da relevância da temática, a literatura da área de administração é carente, o que reitera a necessidade do desenvolvimento de pesquisas nesse sentido, uma vez que podem fornecer instigantes rumos para a compreensão das raízes de uma série de problemas organizacionais atuais, como as ambigüidades entre o perfil requerido dos trabalhadores e as condições reais de trabalho, a questão da valorização da mão-de-obra em contexto de redução de níveis hierárquicos, o impasse da democratização organizacional em ambiente historicamente autoritário, entre outros inúmeros exemplos.

O presente ambiente econômico impõe desafios consideráveis às organizações atuais, o que também é sentido na empresa analisada; contudo esse não é o tipo de influência neutra, da qual a organização apenas sofre as conseqüências; muito pelo contrário, os discursos disseminados incorporam esses dois elementos e em vários momentos deixam claro que se há responsabilidade pelos empregos ceifados, 
esta se deve a fatores externos, que obrigam a organização a adotar tecnologia de última geração, convenientemente poupadora de mão-de-obra. Vale ressaltar que a utilização desse tipo de tecnologia é opção racional do empresariado, que vê seus índices de produtividade se elevarem ao mesmo tempo que passam a depender menos do fator humano (Dejours, 1999). A modernização produtiva se dá mediante a aquisição de equipamentos mais avançados, que conseguem desempenho superior com a utilização de menos recursos, em geral menos trabalhadores também.

Os discursos empresariais são utilizados como mais uma ferramenta a serviço da organização. São destacados fatores como a cooperação, a flexibilidade, a unidade e os resultados, que trazem novo desafio aos empregados, uma vez que agora a organização não se contenta apenas em ser local de trabalho; de certa forma, se propõe a ser amada pelos trabalhadores, em processo claro de criação de identificação e de comprometimento e, mais do que isso, de afetividade. Não se está aqui afirmando que os trabalhadores simplesmente irão sucumbir a esse canto da sereia, mas cabem alguns cuidados profissionais, a fim de preservar os preciosos laços formais que os transformam em trabalhadores centrais.

As práticas de gestão, por sua vez, incorporam apenas parte do que prega o discurso; e dele se tornam antagônicas em uma série de aspectos, em função de estarem essencialmente ligadas ao modo tradicional de gerenciamento. Dessa maneira, caracteriza-se, de certa forma, uma contraposição entre os discursos (que representariam a modernização e os novos valores) e as práticas (reduto do que de mais tradicional se faz nas organizações). É válido ressaltar que, embora tais contradições não escapem a um exercício analítico, na prática funcionam de forma bastante articulada, uma vez que as organizações, a exemplo da EMT, conseguem modernizar aos poucos, sem abrir mão dos elementos tradicionais que julgam relevantes, conforme a perspectiva da Economia Política do Poder (Faria, 2002).

As ambivalências encontradas entre discursos e práticas gerenciais, longe de se apresentarem como elementos isolados, são estreitamente ligadas à realidade que circunda o ambiente organizacional. Especificamente aqui ele se refere aos fatores culturais. A cultura brasileira, que permeou boa parte da análise deste estudo, por suas características peculiares, fornece terreno fértil para que o desenvolvimento de uma gestão como a que se apresenta, fruto em parte do arcaísmo, em parte da inovação, seja bem sucedido, uma vez que é vivenciada pelos trabalhadores, cotidianamente, uma realidade em que dificilmente a 
coerência e a racionalidade predominam; muito pelo contrário, o que se dá normalmente é uma realidade inesperada e desafiadora, repleta de trevas, mas também de luz.

\section{Notas}

${ }^{1}$ Os autores agradecem à Coordenação de Aperfeiçoamento de Pessoal de Nível Superior (CAPES) o apoio recebido, bem como à Rede Interuniversitária de Estudos e Pesquisas sobre o Trabalho (UNITRABALHO), que financiou a pesquisa “Análise da percepção do trabalhador têxtil de Montes Claros: Subsídios para a (re)definição da estratégia de atuação do sindicato dos trabalhadores nas indústrias de fiação e tecelagem”, através da qual foram obtidos importantes dados empíricos que subsidiaram o presente trabalho.

${ }^{2}$ Cada vez mais “a dominação estará baseada muito mais na introjeção dessas normas do que na repressão propriamente dita. A gestão dessa dimensão psicológica de dominação caracterizará essa empresa neocapitalista” (Heloani, 2000, p. 94).

${ }^{3} \mathrm{O}$ termo tácito é utilizado aqui para expressar que o discurso utilizado é o de valorização de mãode-obra, e as práticas, não.

${ }^{4}$ Prestes Motta (1992, p. 46-47) destaca a relevância desse veículo de comunicação na estratégia empresarial, uma vez que "o jornal patronal significa uma tentativa de neutralização dos conflitos entre objetivos de empregadores e empregados em uma época de aumento quantitativo de bens produzidos, de concentração de capital e de parcelamento das tarefas, com a conseqüente desqualificação da mão-de-obra”.

${ }^{5}$ Para maiores detalhes a respeito dos procedimentos metodológicos, consultar Saraiva (2001).

${ }^{6}$ Nome fictício para a organização analisada.

${ }^{7}$ Nome fictício para a família controladora da EMT.

${ }^{8} \mathrm{O}$ fato de ser uma empresa familiar não apenas foi uma vantagem para a EMT, pela preservação de valores ligados aos mais antigos membros da família Santos, como também constituiu um diferencial para as formas de gestão adotadas pelas empresa na sua história. Por ser familiar, o relacionamento com os empregados é de uma natureza próxima, menos formal do que sugerem as relações patrõesempregados em outras organizações, o que é reforçado pela localização das fábricas em cidades de médio porte.

${ }^{9}$ A EMT moderniza seus procedimentos gerenciais, possuindo atualmente em curso um amplo processo de implantação do kaizen, uma técnica gerencial de origem japonesa que tem trazido resultados expressivos à organização, manifestados em especial no que se refere à racionalização de muitas das rotinas operacionais produtivas, o que tem ocasionado, via de regra, redução de mão-deobra empregada. 
${ }^{10} \mathrm{O}$ que aparentemente está envolvido neste mecanismo é a legitimidade. O que legitima a empresa é que ela produz algo socialmente necessário, e ainda cria empregos. Eliminar empregos atualmente, por outro lado, não a deslegitima, porque não é sua responsabilidade, mas do mercado, da tecnologia etc.

${ }^{11}$ A noção de qualidade não é algo intrínseco, relacionado a um padrão ideal. Depende, na verdade, da parcela de mercado a que se destinam os produtos, ao público consumidor específico. A noção de qualidade que está implícita e explícita no texto é a que envolve certificação internacional, ou seja, está inserta em contexto de competitividade internacional.

${ }^{12}$ Um dos desdobramentos da comunicação na EMT é um programa interno denominado papo aberto (nome fictício), que é composto por espaços no interior de cada área produtiva da empresa destinados à fixação de cartazes e avisos destinados a manter os trabalhadores bem informados a respeito do que está acontecendo na empresa, além de uma mesa de reuniões, nas quais ocorrem as reuniões de troca de turno, na qual os empregados que estão deixando o turno passam informações a respeito de como anda o desempenho em relação às quotas de produção daquele dia, dos eventuais problemas das máquinas, entre outros pontos, aos trabalhadores que estão iniciando o turno de trabalho. O contraditório no caso dessa iniciativa é que não há nem tempo hábil para a leitura das informações durante o horário de trabalho - uma vez que os trabalhadores dispõem de pouco tempo ocioso, normalmente usado para a sua alimentação - e muito menos condições objetivas de realizar as reuniões de troca de turno de forma adequada, já que as salas não possuem paredes e nenhuma espécie de tratamento acústico, e as máquinas usadas na produção têxtil são particularmente ensurdecedoras.

${ }^{13}$ Taylor (1990, p. 34) defendeu que “de acordo com leis científicas, a administração deve planejar e executar muitos dos trabalhos de que até agora têm sido encarregados os operários; quase todos os atos dos trabalhadores devem ser precedidos de atividades preparatórias da direção, que habilitam os operários a fazerem seu trabalho mais rápido e melhor do que em qualquer outro caso”.

${ }^{14}$ Uma das formas possíveis de tentar obter a cooperação é por meio do uso do jornal patronal, no qual, de acordo com Prestes Motta (1992, p.47), "sublinha-se a difusão do sentimento de afiliação do empregado à empresa, fazendo transparecer que os objetivos individuais são iguais ou semelhantes aos objetivos da empresa, procurando o consenso e a coesão dos esforços. Paralelamente, procurase desenvolver a criatividade, mediante esclarecimento mais intensivo das oportunidades de carreira. Entende-se, ainda, que é função da informação na empresa garantir a melhor qualidade da decisão em cada escalão da hierarquia. É dessa época a divulgação dos empregados de seu posicionamento no mercado, de dados sobre a qualidade dos produtos da empresa, de demonstrações financeiras, bem como a publicação de artigos dos empregados em geral, ou por área funcional, e de artigos diversos sobre esporte, etiqueta, saúde, previdência etc.”.

${ }^{15}$ Melo (1995) postula que nenhuma forma de controle é absoluta, pois sempre há espaço, em muitos casos extremamente restrito, mas que permitirá a existência de uma relação entre os indivíduos e o exercício de uma certa autonomia.

${ }^{16}$ Esse depoimento ilustra como o humor pode ser usado como forma de resistência às práticas de gestão consideradas injustas pelos empregados. Rodrigues e Collinson (1995) trabalham nessa mesma linha, enfocando o caso de uma organização sindical do setor de telecomunicações, que usa o humor para resistir às atitudes adotadas pela organização. 
${ }^{17}$ Oliveira (1998) defende que ainda que a reestruturação produtiva não possa ser ignorada, a crise do sindicalismo brasileiro possui raízes mais profundas, que vão desde a tendência de acomodação de todas as correntes sindicais ao sistema corporativo até as disputas internas nas centrais sindicais que envolvem o controle dos sindicatos das categorias.

\section{Artigo recebido em 27.05.2003. Aprovado em 16.05.2004.}

Bibliografia

ANSART, P.

Ideologia, conflitos e poder. Rio de Janeiro, Zahar, 1977.

ARANTES, A. A.

O que é cultura popular. 14.ed. São Paulo, Brasiliense, 1998.

BARDIN, L.

Análise de conteúdo. Lisboa, Edições 70, 1995.

BAUDRILLARD, J.

Da sedução. 3.ed. Campinas, Papirus, 2000.

\section{BECKER, H. S.}

Métodos de pesquisa em ciências sociais. 4.ed. São Paulo, Hucitec, 1999.

\section{CHAUÍ, $\mathrm{M}$.}

Conformismo e resistência. 4.ed. São Paulo, Brasiliense, 1989.

Cultura e democracia. 9.ed. São Paulo, Cortez, 2001.

CORRÊA, M. L.;

PIMENTA, S. M.

Estratégias de modernização sistêmica: participação e formação profissional na indústria de Minas

Gerais. In: CONGRESO LATINOAMERICANO DE SOCIOLOGÍA DEL TRABAJO (El trabajo en los umbrales del siglo XXI), 3, Buenos Aires. Anales... Buenos Aires, ALAST, 2000.

DEJOURS, C.

O fator humano. 2.ed. Rio de Janeiro, FGV,1999.

ENRIQUEZ,E.

Imaginário social, recalcamento e repressão nas organizações. Tempo Brasileiro, Rio de Janeiro: Tempo Brasileiro Editora, v.37/37, p.53-97, jan./jun. 1974.

A organização em análise. Petrópolis, Vozes, 1997.

FARIA, J. H.

Economia política do poder: uma proposta teórico-metodológica para o estudo e a análise das organizações. In: ENCONTRO NACIONAL DE ESTUDOS ORGANIZACIONAIS, 2, 2002. Recife. Anais... Recife, Observatório da Realidade Organizacional/ PROPAD/UFPE:ANPAD, 2002.01 CD. 
Ética, moral e democracia: paradoxos da práxis organizacional. In: ENCONTRO NACIONAL DE ESTUDOS ORGANIZACIONAIS, 1, 2000. Curitiba. Anais... Curitiba, CEPPAD/UFPR:ANPAD, 2000, 01 CD.

FARIA, J. H.;

MENEGHETTI, F.K.

Discursos organizacionais. In: ENCONTRO ANUAL DA ANPAD, 25., Campinas. Anais... Campinas, ANPAD, 2001.

FREDDO, A.C.

O discurso da alienação nas organizações. Revista de Administração Pública, Rio de Janeiro: EBAPE/FGV, v.28, n.1, p.2433, jan./mar. 1994.

HELOANI, R.

Organização do trabalho e administração. 3.ed. São Paulo, Cortez, 2000.

LIMA, M. E. A.

Os equívocos da excelência. Petrópolis, Vozes, 1995.

\section{MELO, M. C. O.L.}

Estratégia(s) dos empregado(s) no cotidiano das relações de trabalho: a construção dos processos de autoregulação. In: DAVEL, E. P. B.; VASCONCELLOS, J. G. M. (Orgs.). “Recursos" Humanos e Subjetividade. Petrópolis, Vozes, 1995.
OLIVEIRA, M.A.

Notas sobre a crise do novo sindicalismo brasileiro. São Paulo em Perspectiva, São Paulo: Fundação SEADE, v.12, n.1, p.24-29, 1998.

PAGÈS, M. et al.

O Poder das organizações. São Paulo, Atlas, 1987.

PIMENTA, S. M.

A estratégia da gestão na nova ordem das empresas. In: Recursos Humanos: uma dimensão estratégica. Belo Horizonte: UFMG/FACE/ CEPEAD, 1999.

Participação e qualificação: uma nova sincronia de gestão. Trabalho e Educação, Belo Horizonte: NETE/FAE/ UFMG, n.4, p.99-114, ago./dez. 1998.

POSSENTI, S.

Discurso, estilo e subjetividade. São Paulo, Martins Fontes, 1993.

PRATES, M.A. S.;

BARROS, B. T.

O estilo brasileiro de administrar: sumário de um modelo de ação cultural com base na gestão empresarial. In: PRESTES MOTTA, F. C.; CALDAS, M. P. (Orgs.). Cultura organizacional e cultura brasileira. São Paulo, Atlas, 1997.

PRESTES MOTTA, F. C.

As empresas e a transmissão de ideologia. Revista de Administração de Empresas, São Paulo: EAESP/FGV, v.32, n.5, p.38-47, nov./dez. 1992. 
Organizações: vínculo e imagem. Revista de Administração de Empresas, São Paulo: EAESP/FGV, v.31, n.3, p.5-11, jul./set. 1991.

RODRIGUES, S. B.;

COLLINSON, D. L.

'Having fun'? Humour as resistance in Brazil. Organization Studies, Berlin: Wálter De Gruyer, v.16, n.5, p.739-768, 1995.

\section{SARAIVA, L.A. S.}

Discursos e práticas de gestão em uma empresa do setor têxtil de Minas Gerais. 2001. 152 f. Dissertação (Mestrado em Administração) Faculdade de Ciências Econômicas da Universidade Federal de Minas Gerais, Belo Horizonte.
SOUZA-LOBO, E.

Modelo japonês e práticas brasileiras. In: HIRATA, H. S. (Org.). Sobre o Modelo Japonês. São Paulo, EDUSP, 1993.

TAYLOR, F. W.

Princípios de administração científica. 8.ed. São Paulo, Atlas, 1990.

\section{VELOSO, H. M. et al.}

As transformações do mundo do trabalho. In: PIMENTA, S. M. (Org.). Recursos humanos: uma dimensão estratégica. Belo Horizonte, UFMG/ FACE/CEPEAD, 1999. 